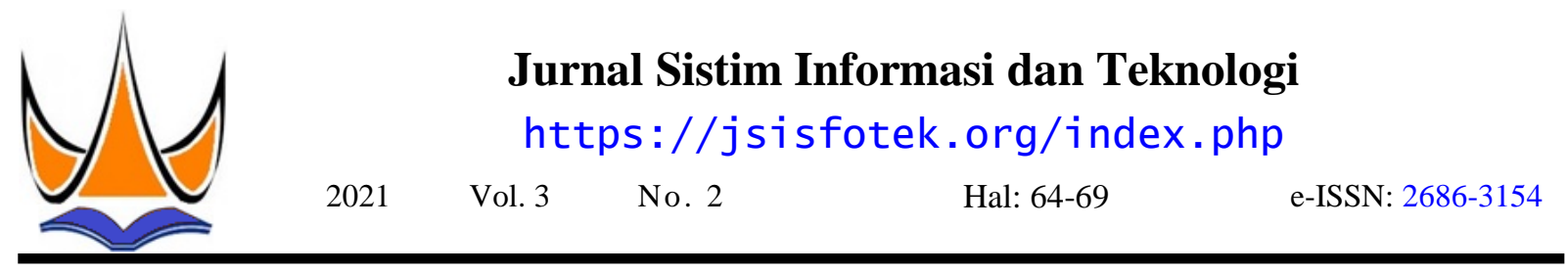

\title{
Sistem Pakar Menggunakan Metode Certainty Factor dalam Akurasi Identifikasi Penyakit pada Paru
}

\author{
Ayu Prima Siska ${ }^{1 凶}$, Yuhandri Yunus ${ }^{2}$, Sumijan \\ 1,2,3 Universitas Putra Indonesia YPTK Padang \\ ayuprima238@gmai1.com
}

\begin{abstract}
Lungs are a very importand part of the human organ, which functions as a place for oxygen exchange. This organ that is located under the ribs has a very heavy task, as well as the pollution of the air we breathe everyday which will cause various diseases in the lungs. Lung disease is a disease that is common to everyone, and there are still many who are less concemed with lung healty, so that is causes many indications of lung diseas. Expert system is a system that uses human knowledge recorded in a computer to solve a problem. The purpose og this study was to datermine the accuracy of disease identification in the lungs using the Certainty Factor method. The date obtained is datae about the symptoms that prove wherher a person has lung disease or not and conduct an analysis of the date, so that later conclusions can be abtained from the facts found using an expert system of the Certianty Factor method. The date obtained is date about the sympyoms thet prove whethera person has lung as a problem solving metric which is a parameter value to show the amount of trust. The result of the research from an expert system on pulmonary disease with pulmonary tuberkolosis (TBC) with a certainty level og $68 \%$. Expert system on lung disease using the Certainty Factor method can make it easien for sufferes to know and handle prevention and handling.
\end{abstract}

Keywords: Expert System, Lung Disease, Certainty Factor, PHP, Database MySQL.

\begin{abstract}
Abstrak
Paru-paru merupakan bagian sangat penting bagi bagi organ tubuh manusia, yang berfungsi sebagai tempat pertukaran oksigen. Organ yang terletak dibawah tulung rusuk ini memang mempunyai tugas yang sangat berat, begitupun dengan tercemarnya udara yang kita hirup sehari-hari yang akan menimbulkan berbagai penyakit pada paru-paru. Penyakit paru-paru merupakan penyakit yang banyak dijumpai pada semua orang, dan masih banyak yang kurang peduli dengan kesehatan paruparu sehingga menyebabkan banyak yang terindikasi penyakit pada paru-paru. Sistem pakar adalah sistem yang menggunakan pengetahuan manusia yang direkam pada komputer untuk memecahkan suatu masalah. Tujuan penelitian ini adalah untuk menetukan akurasi identifikasi penykit paru-paru dengan menggunakan metode Certainty Factor, data yang diperoleh adalah data mengenai gejala-gejala yang membuktikan kepastian atau tidaknya seseorang terkena penyakit paru dan melakukan penganalisaan terhadap data tersebut, sehingga nantinya bisa didapatkan kesimpulan dari fakta-fakta yang ditemui dengan menggunkan sistem pakaar metode Certianty Factor. Sebagai pemecahan masalah yang berbentuk matric yang merupkan nilai parameter untuk menunjukan besarnya kepercayaan. Hasil penelitian dari sistem pakar pada penyakit paru dengan jenis penyakit Tuberkolosis Paru (TBC) dengan tingkat kepastiannya adalah 68\%. Sistem pakar pada penyakit paru dengan menggunakan metode Certainty Factor ini dapat memudahkan penderitanya mengetahui dan menangani pencegahan dan penanganannya.
\end{abstract}

Kata kunci: Sistem Pakar, Paru, Certainty Factor, Php, DatabaseMySQL.

(c) 2021 JSisfotek

\section{Pendahuluan}

Sistem pakar adalah aplikasi berbasis komputer yang digunakan untuk menyelesaikan masalah sebagaimana yang dipirkan oleh pakar. Sistem pakar menggabungkan dua hal yaitu basis pengetahuan dan sistem inferensi. Basis pengetahuan berisi pengetahuanpengetahuan dalam penyelesaian masalah yang diberikan oleh pakar, sistem inferensi digunakan untuk melakukan penalaran dan penarikan kesimpulan [1]. Cara kerja metode Certainty factor adalah dengan Paru-paru merupakan organ utama pada sistem menunjukan ukuran kepastian terhadap suatu fakta atau pernapasa yang bertugas dalam proses respirasi. Paru- aturan. Metode Certainty Factor melakukan penalaran paru berfungsi untuk memasukan oksigen dan layaknya seorang pakar dan mendapatkan nilai mengeluarkan karbondioksida ketika menghirup udara kepercayaan [3]. Proses perhitungan metode Certainty sehingga organ ini layak disebut organ yang sangat Factor dilakukan dengan menghitung nilai perkalian penting bagi manusia [2]. Organ yang terletak dibawa antara nilai cf user dan nilai cf pakar dan menghasilkan tulang rusuk ini memang mempunyai tugas yang sangat nilai cf kombinasi teringgi yang menjadi keputusan berat, belum lagi dengan semakin tercemarnya udara yang kita hirup serta berbagai bibit penyakit yang berkeliaran di udara yang bisa menyebabkan timbulnya penyakit paru seperti gejala-gejala, batuk, sesak napas, dan sakit didaerah dada yang bisa menyebangkan penyakit pada paru seperti radang paru, tuberkolosis paru, asma, dan banyka lagi. Maka dilakukan penelitian dengan menggunakan metode Certainty Factor (CF).

Diterima: 16-10-2020 | Revisi: 31-10-2020 | Diterbitkan: 30-06-2021 | DOI: 10.37034/jsisfotek.v3i2.45 
akhir dari metode Certianty Factor. Kecerdasan Buatan 3. Hasil dan Pembahasan

berasal dari bahasa Inggris "Artificial Intelligance" atau disingkat AI, yaitu Kecerdasan Bautan adalah suatu bagian ilmu komputer yang membuat agar mesin (komputer) dapat melakukan pekerjaan seperti dan sebaiknya yang dilakukan manusia [4]. Salah satu cabang dari (Artificial Intelligance) AI yang dapat diartikan sebagai sebuah perangkat komputer yang memiliki basis pengetahuan untuk bidang tertentu yang menggunkan inferensi yang menyerupai seorang pakar dalam memecahkan sebuah masalah [5]. Dengan adanya sistem pakar menggunkan metode Certainty Factor ini, maka pakar (dokter) bisa dengan mudah mengetahui penyakit paru yang diderita oleh pengidap penyakit tersebut [6].

\section{Metodologi Penelitian}

Penelitian ini merupakan sistem pakar dalam akurasi identifikasi penyakit pada paru [7]. Penelitian dirinci dalam tahapan, dalam bentuk alur dengan urutan langkah-langkahnya disajikan pada Tabel 1.

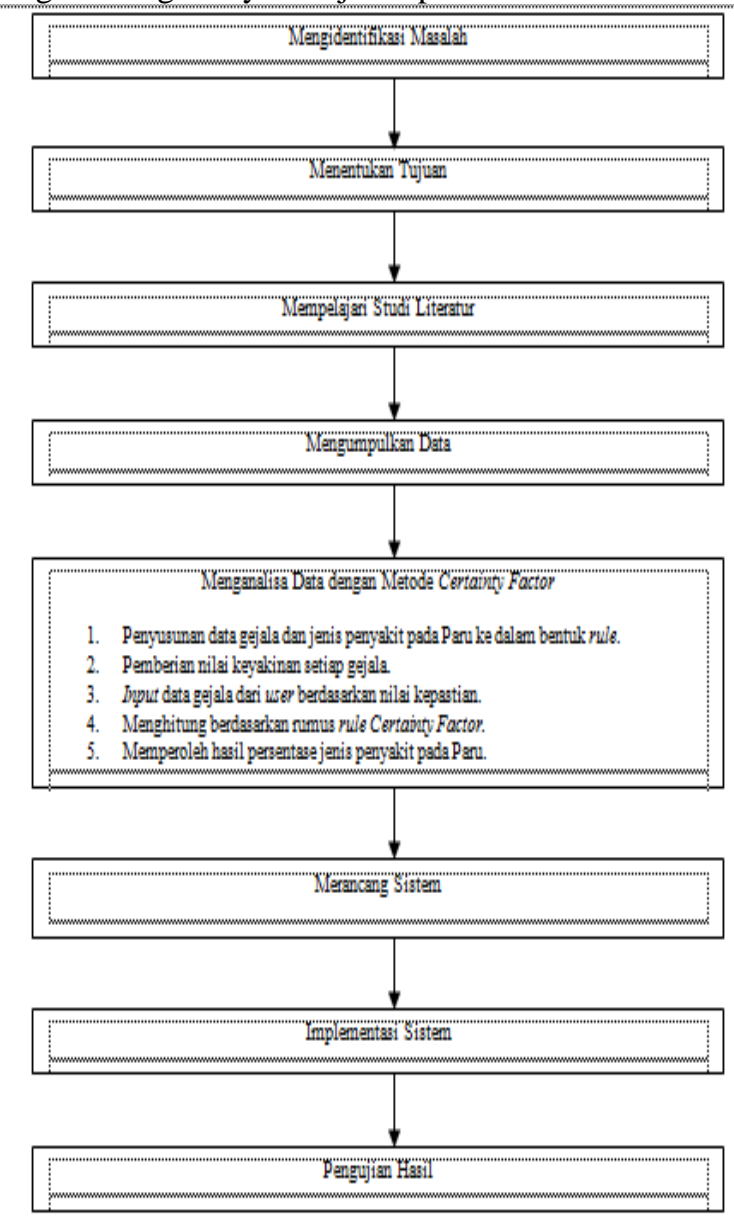

Gambar 1. Kerangka Kerja Penelitian

Penelitian ini membangun sistem pakar dalam melakukan perhitingan menggunkan metode Certianty Factor (CF) [8]. Data yang diolah oleh metode Certianty Factor ini merupkan data-data penyakit informasi tentang jenis, gejala pada penyakit paru. Data penyakit tersebut diperoleh dari hasil wawancara dengan dokter spesialis paru [9].
Objek yang dioleh pada penelitian ini adalah data gejala-gejala yang terdapat dari beberapa jenis penyakit pada paru. Berikut daftar 7 jenis penyakit pada paru yang dapat dilihat pada Tabel 1 sampai dengan Tabel 7.

Tabel 1. Gejala Penyakit Radang Paru

\begin{tabular}{lll}
\hline Nama Penyakit & & \multicolumn{1}{c}{ Gejala } \\
\hline Radang Paru- & a. & Batuk berdahak kuning \\
Paru & b. Sesak nafas \\
& c. Demam lebih seminggu \\
& d. Berat badan turun \\
& e. Keringat malam \\
& f. Nyeri di dada \\
& g. Panas naik turun \\
& h. Sakit kepala dan menggigil. \\
\hline
\end{tabular}

Tabel 2. Gejala Penyakit Tuberkolosis Paru (TBC)

\begin{tabular}{lll}
\hline Nama Penyakit & & \multicolumn{1}{c}{ Gejala } \\
\hline Tuberkolosis & a. & Badan lemah \\
Paru (TBC) & b. Batuk berdarah \\
& c. Nyeri dada \\
& d. & Sesak nafas \\
& e. & Demam \\
& f. & Keringat malam \\
& g. Nafsu makan berkurang \\
& h. & Berat badan turun \\
\hline Tabel 3. Gejala Penyakit Asma \\
\hline Asma & & \\
& & \\
& a. Gejala \\
& b. Batuk berdahak putih \\
& c. Sesak nafas timbul \\
& d. Nyeri dada \\
& e. Bersin dipagi hari \\
& f. Badan lemah mual \\
& g. Muntah \\
& h. Gatal pada tenggorokan
\end{tabular}

Tabel 4. Gejala Penyakit Emfisema

\begin{tabular}{lll}
\hline Nama Penyakit & & \multicolumn{1}{c}{ Gejala } \\
\hline Emfisema & a. & Batuk berdahak putih \\
& b. & Sesak nafas \\
& c. & Demam lebih seminggu \\
& d. & Berat badan turun \\
& e. & Sakit kepala \\
\hline
\end{tabular}

Tabel 5. Gejala Penyakit Legionneres

\begin{tabular}{lll}
\hline Nama Penyakit & & \multicolumn{1}{c}{ Gejala } \\
\hline Legionneres & a. & Batuk berdahak putih \\
& b. & Sesak nafas \\
& c. & Mual \\
& d. & Muntah \\
& e. & Demam lebih seminngu \\
& f. & Panas naik turun \\
& g. & Perut terasa sakit \\
\hline
\end{tabular}

Tabel 6. Gejala Penyakit Bronkitis

\begin{tabular}{lll}
\hline Nama Penyakit & & \multicolumn{1}{c}{ Gejala } \\
\hline Bronkitis & a. & Batuk berdahak putih \\
& b. & Keringat malam \\
& c. & Panas naik turun \\
& d. & Sesak nafas \\
& e. & Suara serak \\
\hline
\end{tabular}

Jurnal Sistim Informasi dan Teknologi Vol. 3 No. 1 (2021) 64-69 
Ayu Prima Siska, Yuhandri Yunus, Sumijan.

Tabel 7. Gejala Penyakit Kanker Paru

\begin{tabular}{lll}
\hline Nama Penyakit & & \multicolumn{1}{c}{ Gejala } \\
\hline Kanker Paru & a. & Batuk berdarah \\
& b. & Sesak napas \\
& c. & Nafsu makan berkurang \\
& d. & Berat badan turun \\
& e. & Radang \\
& f. & Suara serak \\
& g. & Nyeri dada \\
& h. & Pembengkakan leher dan wajah \\
\hline
\end{tabular}

Tabel. 10 Nilai Certianty Factor

\begin{tabular}{ll}
\hline \multicolumn{1}{c}{ Uncertain Term } & Nilai CF \\
\hline Tidak Pasti & 0,0 \\
Hampir Tidak Pasti & 0.2 \\
Kemungkinan Besar Tidak & 0.3 \\
Mungkin Tidak & 0.4 \\
Kemungkinan Kecil & 0.5 \\
Mungkin & 0.6 \\
Kemungkinan Besar & 0.7 \\
Hampir Pasti & 0.8 \\
Pasti & 0.9 \\
Tidak Pasti & 1,0 \\
\hline
\end{tabular}

Selanjutnya akan dilakukan iterasi pada rule berdarkan hasil pengolahan data gejala dan data jenis penyakit maka diperoleh 19 rule untuk diagnosis penyakit paru, seperti pada Tabel10.

\begin{tabular}{ll}
\hline Kode Gejala & \multicolumn{1}{c}{ Nama Gejala } \\
\hline K01 & Batuk brdahak putih \\
K02 & Sesak napas \\
K03 & Demam lebih dari seminggu \\
K04 & Berat badan turun \\
K05 & Keringat malam \\
K06 & Nyeri dada \\
K07 & Panas naik turun \\
K08 & Sakit dibagian kepala \\
K09 & menggigil \\
K10 & Badan lemah \\
K11 & Batuk berdarah \\
K12 & Nafsu makan berkurang \\
K13 & Batuk berdahak putih \\
K14 & Batuk hilang timbul \\
K15 & Bersin dipagi hari \\
K16 & Mual \\
K17 & Muntah \\
K18 & Perut terasa sakit \\
K19 & Suara serak \\
K20 & Radang paru \\
K21 & Pembengkangkan dileher dan wajah \\
K22 & Gata ditenggorokan \\
K23 & Batuk berdahak kuning \\
\hline
\end{tabular}

Dimana K digunakan untuk kode gejala dan ururatan nomor berdasarkan gejala-gejala yang dirasakan oleh pasien penyakit paru. Berdasarkan pengumpulan data dari pakar diperoleh 7 jenis penyakit paru. Setiap jenis penyakit diberikan kode berupa huruf dan angka seperti pada Tabel 9.

Tabel 9. Data Jenis Penyakit Paru

\begin{tabular}{ll}
\hline \multicolumn{1}{c}{ Kode Penyakit } & \multicolumn{1}{c}{ Nama Penyakit } \\
\hline N01 & Radang paru \\
N02 & Tuberkolosis paru \\
N03 & Asma \\
N04 & Emfisema \\
N05 & Legionneres \\
N06 & Bronkitis \\
N07 & Kanker paru-paru \\
\hline
\end{tabular}

Dimana $\mathrm{N}$ digunakan untuk kode penyakit dan urutan nomor berdasarkan berdasarkan penderita terbanyak. Adapun cara untuk mendapatkan tingkat keyakinan Certainty Factor dari sebuah rule yang peneliti gunakan yaitu dengan mewawancairai seorang pakar. Nilai Certainty Factor rule didapat dai interprentasi "term" dari pakar yang diubah menjadi nilai Certianty Factor seperti pada Tabel. 10 berikut ini:
Tabel 11. Nilai Rule

\begin{tabular}{lc}
\multicolumn{2}{c}{ Tabel 11. Nilai Rule } \\
\hline \multicolumn{2}{c}{ Nilai CF } \\
\hline R1 = IF G01 AND G02 AND G03 AND G04 THEN P01 & 0.70 \\
R2 = IF G04 AND G05 AND G06 AND G07 AND G23 THEN P01 & 0.75 \\
R3 = IF G02 AND G03 AND G08 AND G09 THEN P01 & 0.50 \\
R4 =IF G02 AND G03 AND G10 AND G11 THEN P02 & 0.60 \\
R5 =IF G06 AND G10 AND G11 AND G12 THEN & 0.65 \\
R6= IF G04 AND G05 AND G11 AND G12 THEN P02 & 0.80 \\
R7 = IF G02 AND G06 AND G10 AND G13 THEN P03 & 0.70 \\
R8 = IF G10 AND G013 AND G14 AND G15 THEN P03 & 0.80 \\
R9= IF G02 AND G10 AND G15 AND G16 THEN P03 & 0.60 \\
R10 = IF G02 AND G03 AND G04 AND G08 THEN P04 & 0.70 \\
R11 = IF G02 AND G03 AND G08 AND G13 THENP04 & 0.80 \\
R12 = IF G02 AND G03 AND G07 AND G13 THENP05 & 0.60 \\
R13 = IF G07 AND G13 AND G16 AND G17 THEN P05 & 0.55 \\
R14 = IF G03 AND G16AND G17 AND G18 THEN P05 & 0.85 \\
R15 = IF G02 AND G05 AND G07 AND G13 THEN P06 & 0.70 \\
R16= IF G02 AND G07 AND G13 AND G19 THEN P06 & 0.85 \\
R17 = IF G02 AND G04 AND G06 AND G12 THEN P07 & 0.50 \\
R18 = IF G11 AND G12 AND G19 AND G20 THEN P07 & 0.75 \\
R19 = IF G04 AND G12 AND G20 AND G21 THEN P07 & 0.85 \\
\hline
\end{tabular}

Berdasarkan Rule pada Tabel 9 maka akan dilakukan proses perhitungan nilai kepastian jenis penyakit pada pasien 1 yang disajikan pada Tabel 12 .

Keterangan dari setiap rule dari fakta baru:

Rule 1 : Tidak dapat dieksekusi karena ada evidence yang tidak fakta.

Rule 2 : Tidak dapat dieksekusi karena ada evidence yang tidak fakta.

Rule 3 : Tidak dapat dieksekusi karena ada evidence yang tidak fakta.

Rule4: IF G02 ( $\mathrm{CF}=1.0)$ AND G03 ( $\mathrm{CF}=1.0)$ AND G10 $(\mathrm{CF}=1.0)$ AND G11 $(\mathrm{CF}=0.7)$ THEN P02 $(\mathrm{CF}=0.60)$ 


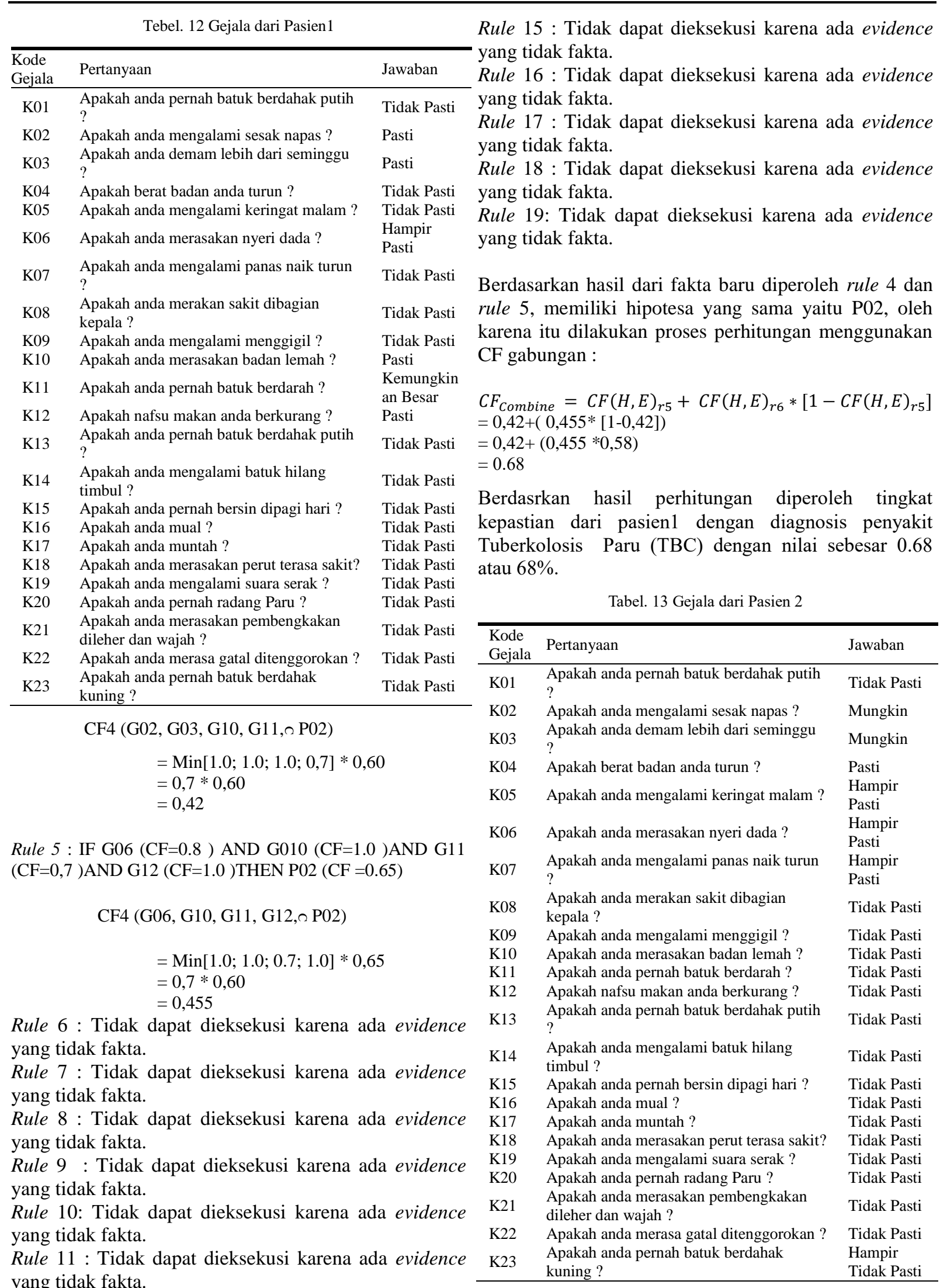

Rule 12: Tidak dapat dieksekusi karena ada evidence Keterangan dari setiap rule dari fakta baru: yang tidak fakta.

Rule 13 : Tidak dapat dieksekusi karena ada evidence yang tidak fakta.

Rule 1:Tidak dapat dieksekusi karena ada evidence yang tidak fakta.

Rule 14 : Tidak dapat dieksekusi karena ada evidence yang tidak fakta.

Jurnal Sistim Informasi dan Teknologi Vol. 3 No. 1 (2021) 64-69 
Rule 2 : IF G04 (CF=1)AND G05 (CF=0,8)AND G06 Tabel 14 dari dua kasus menunjukan hasil perhitungan $(\mathrm{CF}=0,8)$ AND G07 ( $\mathrm{CF}=0.8)$ THEN P01 $(\mathrm{CF}=0.75)$

CF4 (G04, G05, G06, G07, ค P01)

$$
\begin{aligned}
& =\operatorname{Min}[1 ; 0,8 ; 0,8 ; 0,8] * 0,75 \\
& =0,8 * 0,75 \\
& =0,6
\end{aligned}
$$

Rule 3 : Tidak dapat dieksekusi karena ada evidence yang tidak fakta.

Rule4 : Tidak dapat dieksekusi karena ada evidence yang tidak fakta

Rule 5 : Tidak dapat dieksekusi karena ada evidence yang tidak fakta

Rule 6 : Tidak dapat dieksekusi karena ada evidence yang tidak fakta.

Rule 7 : Tidak dapat dieksekusi karena ada evidence yang tidak fakta.

Rule 8 : Tidak dapat dieksekusi karena ada evidence yang tidak fakta.

Rule 9 : Tidak dapat dieksekusi karena ada evidence yang tidak fakta.

Rule 10 : Tidak dapat dieksekusi karena ada evidence yang tidak fakta.

Rule 11 : Tidak dapat dieksekusi karena ada evidence yang tidak fakta.

Rule 12 : Tidak dapat dieksekusi karena ada evidence yang tidak fakta.

Rule 13 : Tidak dapat dieksekusi karena ada evidence yang tidak fakta.

Rule 14 : Tidak dapat dieksekusi karena ada evidence yang tidak fakta.

Rule 15 : Tidak dapat dieksekusi karena ada evidence yang tidak fakta.

Rule 16 : Tidak dapat dieksekusi karena ada evidence yang tidak fakta.

Rule 17 : Tidak dapat dieksekusi karena ada evidence yang tidak fakta

Rule 18 : Tidak dapat dieksekusi karena ada evidence yang tidak fakta.

Rule 19 : Tidak dapat dieksekusi karena ada evidence yang tidak fakta.

Berdasarkan hasil dari fakta baru diperoleh rule 2, memiliki hipotesa yang sama yaitu P01, dengan nilai 0.6 atau $60 \%$ terkena penyakit Radang Paru-Paru.

Pengujian terhadapa 2 data pasien dilakukan untuk melihat seberapa besar tingkat akurasi hasil sistem pakar berbasis online. Dengan hasil yang diberikan pakar. Dalam pengujian ini yang menjadi hasil pengujian adalah penyakit paru dan jenis penyakit paru yang bersumber dari data pasien penyakit paru di Rumah sakit umum daerah Sijunjung. Berikut Tabel hasil perhitungan dua data pasien penyakit paru.

Tabel 14. Hasil Perhitungan 2 data Pasein

\begin{tabular}{cccc}
\hline $\begin{array}{c}\text { Kode } \\
\text { pasien }\end{array}$ & $\begin{array}{c}\text { Kode } \\
\text { Penyakit }\end{array}$ & Nama Penyakit & Nilai CF \\
\hline Pasien 1 & N02 & Tuberkolosis Paru & $68 \%$ \\
Pasien 2 & N01 & Radang Paru & $60 \%$ \\
\hline
\end{tabular}

dua data uji coba pasien penyakit paru menggunakan etode certainty factor dengan proses perhitungan secara manual. Hasil nilai certainty factor tersebut didapatkan dari proses pencarian fakta dengan rule terhadap 7 jenis penyakit pada paru besera kegaja-gejalanya.

Penelitian ini juga didukung dengan pembangunan sistem tang diaplikasikan dengan menggunakan pemrograman PHP dan database MySQL. Ini lah bentuk tampilan halaman depan pada sistem pakar menggunakan metode certainty factor dalam akurasi identifikasi penyakit paru pada Gambar 2.

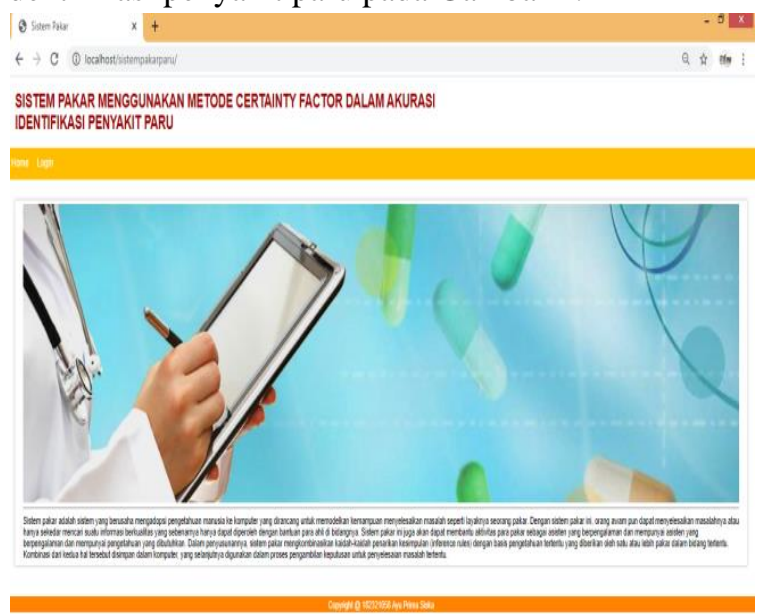

Gambar 2. Penyakit Paru

Pada gambar 2 menampilkan tampilan awal pada sistem pakar menggunakan metode certianty factor dalam akurasi identifikasi penyakit paru.

Tampilan halaman konsultasi pasien pada Gambar 3.

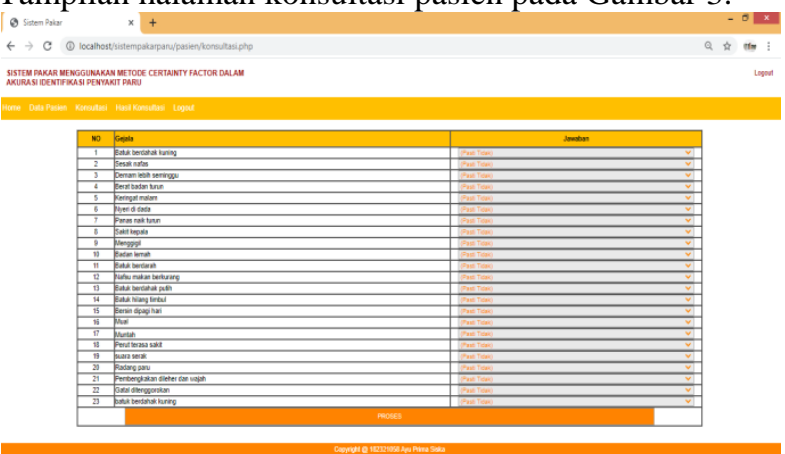

Gambar 3. Tampilan Konsultasi Pasien

Gambar 3 menampilkan proses konsultasi user dengan sistem pakar, yaitu user memilih jawaban pada tabel konsultasi terhadap pertanyaan-pertanyaan yang telah disediakan di menu konsultasi.

\section{Kesimpulan}

Berdasarkan penelitian dan pembahasan yang dilakukan maka dapat disimpulkan beberapa hal yaitu: dengan adanya sistem pakar menggunakan metode certainty factor dalam akurasi identifikasi penyakit paru ini pasien dapat melakukan diagnosa secara dini berdasarkan gejala-gaejala penyakit pada paru, dengan

Jurnal Sistim Informasi dan Teknologi Vol. 3 No. 1 (2021) 64-69 
adanya penerapan aplikasi ini dapat mambantu masyarakat umum untuk mengetahui jenis-jenis penyakit paru pada pasien dengan cepat tanpa harus bertemu lengsung dengan dokter, sistem pakar ini juga dapat membantu mengurangi ketidaktahuan pengguna terhadap penyakit paru dan dapat menghasilkan informasi yang tepat dan berguna untuk penggunanya.

\section{Daftar Rujukan}

[1] Saputra, A. (2016). Pengembangan Sistem Pakar Identifikasi Penyakit Paru-Paru Menggunkan Metode Certainty Factor. IT Journal, 4(2).

[2] Kurniawan, B., Utami, Y. R. W., Saptomo, W. L. Y. (2017). Sistem Pakar Diagnosa Penyakit Paru Pada Anak dengan Menggunakan Metode Certainty Factor. Jurnal TIKomSiN, 5(2).

[3] Cahyadi, B. (2018). Sistem Pakar Diagnosis Penyakit Paru Menggunakan Metode Certainty Factor dengan Mesin Inferensi Forward Chaining Berbasis Android. JATI: Jurnal Mahasiswa Teknik Informatika, 2(1).

[4] Gustinaldi. (2019). Aplikasi Sistem Pakar Diagnosis Penyakit Paru-Paru dengan Menngunakan Metode Forward Chaining di
RSUD Teluk Kuantan. Jurnal Perancanaan, Sains, Teknologi dan Komputer, 2(1), 58-66.

[5] Santi, I. H., \& Andari, B. (2019). Sistem pakar untuk Mengidentifikasi Jenis Kulit Wajah dengan Metode Certianty Factor. INTENSIF: Jurnal Ilmiah Penelitian dan Penerapan Teknologi Sistem Informasi, 3(2). DOI: https://doi.org/10.29407/intensif.v3i2.12792 .

[6] Kuryanti, S. J., \& Septiani, M. (2018). Sistem Pakar Untuk Mendiagnosis Penyakit Saluran Pernapasan Pada Anak (Studi Kasus: RSAB Harapan Kita Jakarta). Sinkron Jurnal \& Penelitian Teknik Informatika. 2(2)

[7] Aini, N., Ramadiani, R., \& Hatta, H. R. (2017). Sistem Pakar Penyakit Tuberkulosis. Informatika Mulawarnan, 12(1). DOI: http://dx.doi.org/10.30872/jim.v12i1.224 .

[8] Sumiati., Badriyah, R. D. M., \& Ariani, A. (2017). Sistem Pakar Untuk Diagnosis Penyakit Paru-Paru Menggunakan Metode Certainty Factor di Puskesmas Citangkil. Jurnal ProTekInfo, 4(1), 34-42.

[9] Wahyuni, S. N., \& Garjita, L. (2019). Perancangan Sistem Pakar Diagnosis Penyakit Gigi Menggunakan Algiritma Bayes. IJUBI Indonesian Journal of Business Intelligance. 2(1), 9-17. DOI: http://doi.org/10.21927/ijubi.v2i1.1020 . 